The development and validation of a short form of the Australian version of the Career Development Inventory

Authors: Peter A. Creed Griffith University, Australia

Wendy Patton Queensland University of Technology, Australia

Contact: Associate Professor Peter A Creed

School of Applied Psychology

Griffith University - Gold Coast

PMB 50 GCMC

Gold Coast, Queensland Australia 9726

Telephone: +61755528810

Facsimile:+61 755528291

Email: p.creed@griffith.edu.au 


\title{
The development and validation of a short form of the Australian version of the Career Development Inventory
}

\begin{abstract}
This study utilised a sample of 2173 high school students, enrolled in Years 8-12, to develop a 33-item shortened form (CDI-A-SF) of the Australian version of the 72item Career Development Inventory (CDI-A). The long form of the CDI-A has been criticised for its length, difficulty and repetitive nature. The CDI-A-SF was devised with reference to content coverage and statistical criteria. Factor analysis of the short form indicated that, at the item level, subscale items loaded on their respective factors, and at the subscale level, the attitudinal and cognitive subscales loaded on the appropriate factors. Strong correlations were found between the CDI-A-SF and the CDI-A at the subscale, composite scale and total scale levels. Internal reliability coefficients for the CDI-A-SF at all levels were satisfactory to good. Initial validity for the CDI-A-SF was demonstrated by associations in the expected direction with career decidedness, self-esteem and decision-making self-efficacy, and by age and gender differences in the expected directions. The CDI-A-SF shows promise as a measure of career maturity where it is not possible or inappropriate to use the full version, although further research needs to replicate the findings and further test its validity.
\end{abstract}

Keywords: Career Development Inventory, CDI-A, career maturity, career planning, career exploration, short form 
The career development theory of Super (1957, 1990), and its dominating construct of career maturity, has received wide attention since its introduction, and has experience renewed interest in recent years (Patton \& Lokan, 2001). Career maturity is central to a developmental understanding of career behaviour, and involves awareness of an individual's level of career progress in relation to his/her career related development tasks (Crites, 1976). Career maturity can be broadly defined as the individual's readiness to make informed, age-appropriate career decisions and manage his/her career development tasks (Savickas, 1984). This definition encompasses the individual's capacity to make appropriate career choices, and is predicated on the individual's awareness of what is required to make a career decision and the degree to which resultant choices are both realistic and consistent over time (Levinson, Ohler, Caswell, \& Kiewra, 1998). Crites' (1971) model of career maturity proposed that career maturity consisted of both affective and cognitive dimensions, with the cognitive dimension being composed of decision making skills and the affective dimension being attitudes about the career decision making process. The notion of career maturity has been valued for its practical utility (Raskin, 1998), and has been seen as an important construct to be assessed and developed in counselling and education programs for adolescents (Ohler \& Levinson, 1994).

A number of assessment instruments have been developed to measure the construct of career maturity. Levinson et al. (1998) and Bingham and Krantz (2001) have each identified six scales in the literature. Further, the construct of career maturity itself has received renewed research interest, with a special issue of The Career Development Quarterly being devoted to it in 1998. Accordingly, assessment of the construct is also a subject of vigorous research, with a shortened and revised version of one instrument, the Career Maturity Inventory - Revised being published in 1995 (Crites 
$\&$ Savickas). One of the more widely used scales for measuring career maturity is the 120-item Career Development Inventory (CDI; Super, Thompson, Lindeman, Jordaan, \& Myers, 1981; Super, Thompson, Jordaan, Lindeman, \& Myers, 1984). This scale, which was developed in the USA, incorporates two attitudinal subscales, namely Career Planning (CP) and Career Exploration (CE), two general cognitive subscales, Decision Making (DM) and World of Work Information (WW), and one specific cognitive subscale, Knowledge of Preferred Occupational Group (PO). Typically, the CP and CE subscales are summed to provide a composite attitudinal score, Career Development Attitude (CDA), and WW and DM are summed to provide a composite cognitive score, Career Development Knowledge (CDK).

An Australian version of the Career Development Inventory (CDI-A; Lokan, 1984) was developed from the USA version. The CDI-A incorporates spelling, terminology, and references to institutions, information sources and occupational conditions that are appropriate to an Australian setting. There are also differences in the scoring methods, with the CDI-A using a 4-point response format for the CP subscale rather than five points, and not weighting items in the CE subscale. Although, the main difference between the CDI-A and the CDI is that the CDI-A contains only 72 items, as opposed to the 120 in the CDI. This occurs because the CDI-A does not incorporate a PO subscale, and contains fewer items in the CE (16 rather than 20) and DM (12 rather than 20) subscales than the CDI.

Psychometric data on the CDI are reported in two Manuals (High School version Form S, Thompson \& Lindeman, 1981; College and University version - Form CU, Thompson \& Lindeman, 1982), a Technical Manual (Thompson \& Lindeman, 1984), and published articles and reviews (e.g., Betz, 1988; Savickas \& Hartung, 1996; Super, Osborne, Walsh, Brown \& Niles, 1992). Satisfactory internal reliability 
coefficients have been reported for the CDA and CDK composite scores, and for the $\mathrm{CP}$ and $\mathrm{CE}$ subscales, while less than adequate data (i.e., $r<.70$ ) have been reported for the WW, DM and PO subscales (Savickas \& Hartung). Content validity for the CDI has been demonstrated using exploratory factor analysis, with the two attitudinal scales, $\mathrm{CP}$ and $\mathrm{CE}$, correlating more highly with one another than with either of the cognitive scales (WW, DM) (Thompson \& Lindeman). Questions have been raised regarding the dimensionality of the PO subscale, with one study (Savickas, 1984) finding that PO loaded with the attitudinal rather than the cognitive scales as would be expected. Construct validity of the CDI has primarily been tested by studies examining concurrent validity with other career-related variables, such as career development (Luzzo, 1993), and vocational identity (Wallace-Broscious, Serafica, \& Osipow, 1994), although predictive validity has also been assessed and supported (e.g., Lewis, Savickas, \& Jones, 1996). In the most recent review of the CDI, Savickas and Hartung (1996), although acknowledging the weaknesses of the cognitive subscales, concluded that the CDI was a sound measure of readiness to make a vocational choice.

The CDI-A has been widely used in Australia (e.g., Clayton \& Fletcher, 1994; Creed \& Patton, 2003; Levy, 1987; Lokan \& Biggs, 1982; Patton \& Creed, 2001) as well as in other countries (e.g., South Africa; Patton, Watson, \& Creed, In press). Psychometric data are provided in the Australian Manual (Lokan, 1984). These include internal reliability coefficients for the subscales and total score of the CDI-A in the range of .73-.90 for an age 14 sample, and .65-.90 for a Year 11 sample, which represent similar reliabilities to those reported for the CDI (Pinkney \& Bozik, 1994). Construct validity is indicated by appropriate age differences in scores, with older students scoring higher than younger students, and a factor analysis yielded the 
expected two attitudinal and cognitive factors. In a large and diverse sample $(N=$ 1,971) of Australian high school students, Patton and Creed (2001) reported internal reliability coefficients of .91 (CP), .78 (CE), .77 (WW), .67 (DM), .91 (CDA) and .84 (CDK), and found expected maturity increases across school grades, expected higher scores for young females over young males, and expected associations between the CDI-A and career certainty and career indecision (as measured by the Career Decision Scale, Osipow, 1987).

Despite the CDI-A being a shorter test than the CDI, concerns have still been raised as to its length, the repetitive nature of some of the items, the amount of reading required in the vignette item-formats, the complexity of language required for younger age groups (Levinson et al., 1998), and the difficulty of completing the WW and DM subscales (Lokan, 1984, p. 44). These drawbacks are seen to limit its usefulness as a research tool especially, but also limit its value in applied settings, particularly with young people. Our own research indicates that it is difficult for young people to complete the CDI-A in a 40 minute school period and that students respond negatively to the demands of completing the two cognitive subscales. These issues have also been raised by Bingham and Krantz (2001). Other career related scales have been produced in short-form version (e.g., the Career Maturity Inventory - Revised, Crites \& Savickas, 1995; the Career Decision-making Self-efficacy scale, Betz, Klein, \& Taylor, 1996), and it will be very useful to have a reduced form career maturity scale that captures the relevant constructs. The present study's aim is to devise a short form of the CDI-A that has comparable psychometric properties to the parent scale which can be used in situations in which it is not possible to use the full 72-item version. This is especially important as many reviewers highlight the need to 
provide data on the development of career maturity with younger adolescents (Bingham \& Krantz).

\section{Method}

\section{Participants}

Participants were 2173 secondary school students enrolled in Grades 8-12 in three schools in the south-eastern part of Australia. The schools were suburban based in medium sized cities. The first school could be categorised as public, low socioeconomic status $(N=1006)$, the second as public, medium/high socioeconomic status $(N=593)$, and the third as private, medium socioeconomic status $(N=574)$. The students had a mean age of 15.21 years $(S D=1.50$ years), and comprised $54 \%$ female and 46\% male, with $568(26 \%)$ in Grade 8, 396 (18\%) in Grade 9, 459 (21\%) in Grade 10, 419 (19\%) in Grade 11, and 331 (15\%) in Grade 12.

\section{Measures}

Career Maturity: The Australian version of the Career Development Inventory (CDI-A; Lokan, 1984) has 72 items, and is designed for students in Years 8-12. It measures several aspects of career development, including career planning orientation, awareness and use of resources, knowledge of the career development process, knowledge of the world of work, and knowledge and use of decision making principles. Four subscales, two composite scales and a total scale score can be calculated for the CDI-A.

The first subscale is Career Planning (CP), which covers two main domain areas, of Planning Orientation (CP-PO; 12 items, sample items of "How much time and thought have you given choosing a regular adult occupation?" with response format 
endpoints of "I give less time and thought to this than most of my classmates" and "I give more time and thought to this than most of my classmates") and Specificity of Information (CP-SI; 8 items; sample item of "Keeping in mind the type of job you think you might like to go into when you've finished your schooling, how much do you know about the abilities needed for that kind of occupation?" with endpoints of "I know hardly anything about this aspect" and "I know a great deal about this aspect"). The second subscale is Career Exploration (CE), which also covers two main domain areas, of Resource Awareness (CE-RA; 8 items, sample item of "To which of the following sources would you go for information or help in making your plans for work or further education: father, mother, uncles, aunts etc?" with endpoints of "I would be very unlikely to go to or use this source" and "I would be very likely to use this source"), and Resource Usage (CE-RU; 8 items, sample item of "Which of the following sources have already given you, or directed you to, helpful information for making your plans for the future: brothers, sisters, cousins or friends?" with endpoints of "I have consulted this source, but have obtained little or no useful information" and "I have not yet consulted this source"). The third subscale is World of Work Information (WW; 24 items, sample item "The best way to find out about yourself and the world around you is to:" with response options of "Take some aptitude tests/Ask other people what they think/Read newspapers and magazines/Try yourself out in many different situations and activities). The fourth subscale is Career Decision Making (DM; 12 items, sample item “B.D.’s interest in and skill at helping others has become the most important self-picture. Which occupation should B. D. probably not be considering?" with response options of "Nurse's aide/Recreation worker/Caretaker/Teacher's aide"). The two composite scales are Career Development Attitude (CDA; which is formed by summing CP and CE) and Career 
Development Knowledge (CDK; WW and DM combined). A Career Orientation Total (COT) can also be calculated. This score is obtained by summing CDA and CDK. Subscale, composite and total scale reliability coefficients reported in the Manual (Lokan) are in the range .73-.90 for an age 14 sample, and .65-.90 for a Year 11 sample, which represent similar reliabilities to those reported for the American inventory (Pinkney \& Bozik, 1994).

Validity evidence for the CDI-A is reported in the Manual. Construct validity is indicated by appropriate age differences in scores, with older students scoring higher than younger students. Inter-scale correlations are between .50 and .70 , and a factor analysis yielded the expected two factors. The manual also refers readers to the studies conducted on the US original version. The CDI-A is also available in a slightly modified and updated version (Lokan \& Bryde, 1993). The differences between the two versions are very minor with the later version using updated labour market terminology that has been outdated since the 1983 version was published (e.g., book-keepers using a calculator and not a slide rule; referring to an usher and not a porter). This is the version of the CDI-A reported in the current study.

Career Decision-Making. The Career Decision Scale (CDS; Osipow, Carney, Winer, Yanico, \& Koschier, 1976) was used to measure decision-making readiness. The 19-item CDS inventory consists of two subscales, the 16-item CDS-Indecision (CDS-I) subscale that provides a measure of career indecision, and the 2-item CDSCertainty (CDS-C) subscale that indicates the degree of certainty felt in having made a career decision. There is also an open-ended question that allows respondents to put their concerns in their own words, which was not reported in this study. Participants respond to items by indicating on a four-point response format whether the item was "not at all like me" through to "exactly like me". Higher scores indicate more 
indecision and more certainty respectively. Internal consistency coefficients have been consistently reported in the .80 range (Hartman, Fuqua \& Hartman, 1983). Internal reliability coefficients calculated in the present study were .89 for the CDS-I and .73 for CDS-C.

Self-esteem. The Rosenberg Self-esteem Scale (RSE; Rosenberg, 1965) was used to provide a measure of global self-worth. The RSE contains 10 items (e.g., "I feel that I have a number of good qualities"), and participants were asked to rate how strongly they agreed or disagreed with each. Answers were scored on four-point response format using descriptors of "strongly agree" to "strongly disagree", with lower scores indicating greater self-worth. The internal reliability coefficient for the present study was .84 .

Career Decision-making Self-efficacy. The 25-item short version of the Career Decision-making Self-efficacy scale (CDMSE-SF; Betz et al., 1996) measures confidence regarding ability to make career-oriented decisions. A sample item is, "How confident are you that you could determine what your ideal job would be?". Participants rated their level of confidence on a 5-point scale, with end-points of "no confidence at all" to "complete confidence". Higher scores indicate more careerrelated confidence. Betz et al. reported adequate validity for the scale, and indicated satisfactory internal reliabilities ranging from .73 to .83 . The internal reliability for the present study was .95 .

\section{Procedure}

The data reported here represent aggregated data taken from a larger scale study examining the correlates of career maturity for high school age students (see Patton \& Creed, 2001). Survey forms containing the scales used in the study and asking 
demographic questions (e.g., age and gender) were administered to students in Grades 8-12 in the secondary schools that participated in the study. The classroom teachers, who had been provided with instructions regarding the administration protocol, administered the survey forms.

\section{Results}

Development of the CDI-A-SF: Item Analysis

In developing a shortened version (CDI-A-SF) of the CDI-A, consideration was given to (a) construct coverage (versus narrowness of coverage), (b) the corrected item-own and item-other domain total correlations for the attitudinal scales, and the item-difficulty scores for the cognitive scales, and (c) selecting items that only loaded on the appropriate factor. While some researchers have suggested that at least 10 items are required for a reliable scale (Kline, 2000), others have maintained that this can be achieved with as few as 4-6 items (Hinkin, 1998). As a consequence, a reduced number of items between 6-10 was targeted for each subscale of the CDI-A, with the overall aim of producing a shortened version of the 72-item CDI-A containing from 24-40 items.

The Career Planning subscale comprises the two domains of Planning Orientation and Specificity of Information. With regard to the Planning Orientation (CP-PO) domain, 12 items cover the content areas of seeking authoritative information, consulting adults, having exploratory experiences, earning money, job seeking, choosing subjects, job and career, and life after school. Items 1-8 share the same stem question, Items 9-11 share the same stem question, and Item 12 has its own stem. To ensure adequate construct coverage, items from each of these three clusters were retained. These were Items 2-4, 9, 11 and 12. All had strong item-own domain total 
correlations (ranging from .63-.71) and represented a spread of coverage of the construct. As an example, Item 11 ("How much time and thought have you given to choosing a career in general") was chosen over Item 10 ("How much time and thought have you given to choosing a regular adult occupation"). The items were highly correlated $(r=.59)$, they represented conceptual overlap (choosing an occupation vs. choosing a career), although Item 11 was marginally more highly correlated with the CP-PO domain total (.71 vs. .69). With regard to the Specificity of Information (CP-SI) domain, the content cover the self-knowledge areas of job duties, ability, working conditions, training, entry, pay, advancement and hours. All 8 items shared the same stem question. Items $13,14,15$ and 19 were retained, with itemdomain total correlations ranging from .73-.81.

The Career Exploration subscale comprises the two domains of Resource Awareness and Resource Use. For Resource Awareness (CE-RA), the 8 items cover possible sources of advice from family, friends, teachers, counsellors, printed material and media, and job incumbents. All items share the same stem question. Items 23-25 and 28 were retained. Item-domain total correlations ranged from .61-.66. For the Resource Use (CE-RU) domain, the 8 items cover actual sources of advice. All items share the same stem question. Items 33-36 were retained, with item-domain totals ranging from .55-.66.

The World of Work Information (WW) subscale covers content areas of information on exploratory methods and activities, life stages, developmental tasks, job satisfaction, job seeking, occupational fields, training and tools. All 24 items used a four-option multiple-choice format. For these types of items, the optimum item difficulty index is .63 (Gregory, 2000). To ensure a spread of item difficulty, items were chosen that ranged around the optimal item-difficulty score and included items 
that were easier than optimal to more difficult than optimal to answer. Eight items $(39,41,42,43,44,46,47,51)$ were selected that had item-difficulty indices ranging from .56-.80. The full range of item difficulty indices was .19-.82. For the Career Decision-Making (DM) subscale, the 12 items covered the domain areas of understanding the relative importance of different types of occupational information, and personal and situational characteristics. These items also used a four-option multiple-choice format. Seven items $(62,63,64,65,66,70$ and 71$)$, with an itemdifficulty range of .47-.64 were retained. The full item-difficulty range here was .3267.

Development of the CDI-A-SF: Factor Analysis

The items selected for the attitudinal domains (CP-PO, CP-SI, CE-RA, CE-RU) of the CDI-A-SF were subjected to a principal axis factor analysis with an oblique (direct oblimin) rotation. An oblique solution, which simplifies the factors and variables by allowing the factors to be correlated, was sought as the scales measure related components of career maturity. Factor loadings after oblique rotation, eigenvalues, percentage of variance explained and inter-factor correlations are reported in Table 1. For this analysis, the KMO measure of sampling adequacy was .89 and the Bartlett's Test of Sphericity was significant $(<.001)$, indicating the data were suitable for factor analysis. Four factors were rotated (to reflect the four CDI-ASF domains). This solution was factorially simple and interpretable. Examination of the pattern matrix indicated that the domain items loaded onto their respective factors, although two cross-loadings were identified between PO and SI, which were not considered material as both domains of PO and SI constituted the CP subscale. All factors had eigenvalues greater than one, and accounted for $57.48 \%$ of the variance. 
As factor analysis is not recommended for items that are dichotomously scored (Gorsuch, 1983), no factor analysis at the item level was conducted for the cognitive subscales, which are scored as correct or incorrect. Thus, these 33 items were accepted for inclusion in the CDI-A-SF.

Table 1

Principal axis factor estimates of the oblique (direct oblimin) factor loadings for the 18-item attitudinal component of the CDI-A-SF; $N=2173$

\begin{tabular}{|c|c|c|c|c|c|}
\hline \multirow{2}{*}{\multicolumn{2}{|c|}{ Domain Item $^{1}$}} & \multicolumn{4}{|c|}{ Factor } \\
\hline & & SI & RA & RU & $\mathrm{PO}$ \\
\hline \multirow[t]{6}{*}{ 1. PO } & 2 & .19 & .10 & .09 & .34 \\
\hline & 3 & -.04 & -.02 & -.00 & .79 \\
\hline & 4 & -.05 & .03 & .05 & .75 \\
\hline & 9 & .10 & .10 & -.04 & .52 \\
\hline & 11 & .33 & .08 & .00 & .38 \\
\hline & 12 & .33 & .05 & .07 & .34 \\
\hline \multirow[t]{4}{*}{ 2. SI } & 13 & .81 & -.01 & -.03 & .01 \\
\hline & 14 & .85 & .01 & -.05 & .04 \\
\hline & 15 & .83 & -.03 & -.02 & -.02 \\
\hline & 19 & .59 & .00 & .18 & -.01 \\
\hline \multirow[t]{4}{*}{ 3. RA } & 23 & -.07 & .76 & -.08 & .05 \\
\hline & 24 & -.06 & .74 & -.04 & .03 \\
\hline & 25 & .09 & .49 & .18 & -.04 \\
\hline & 28 & .12 & .40 & .12 & -.04 \\
\hline \multirow[t]{4}{*}{ 4. RU } & 33 & .04 & .19 & .56 & -.06 \\
\hline & 34 & -.02 & -.02 & .47 & .22 \\
\hline & 35 & -.02 & -.08 & .55 & -.01 \\
\hline & 36 & .09 & .09 & .52 & -.03 \\
\hline \multicolumn{2}{|c|}{ Eigenvalue } & 5.89 & 1.70 & 1.54 & 1.22 \\
\hline \multicolumn{2}{|c|}{$\%$ Variance } & 32.69 & 9.45 & 8.57 & 6.77 \\
\hline \multicolumn{2}{|c|}{ Correlation 1.} & .50 & .44 & .30 & - \\
\hline & 2. & - & .36 & .44 & - \\
\hline & 3. & - & .35 & - & - \\
\hline
\end{tabular}

Note: ${ }^{1}=$ Item numbers from original CDI-A; PO = Planning Orientation, $\mathrm{SI}=$ Specificity of Information, RA = Resources Awareness, RU = Resource Use 
Comparison of CDI-A-SF and CDI-A Factor Structure

To determine whether the factor structure of the CDI-A-SF was consistent with the original factor structure of the CDI-A, a principal axis factor analysis with an oblique (direct oblimin) rotation was conducted on the Years 8-12 and Total samples using the four attitudinal domain totals (PO, SI, RA and RU) and the two cognitive subscale totals (WW and DM). Summary data for these analyses are reported in Table 2. Factor loadings after oblique rotation, eigenvalues, percentage of variance explained and inter-factor correlations are presented in Table 3. For this analysis, the KMO measures of sampling adequacy ranged between .64-.70 and all Bartlett's Tests of Sphericity were significant $(<.001)$. Two factors were rotated (to reflect the attitudinal and cognitive dimensions). These solutions were factorially simple and interpretable. Examination of the pattern matrix indicated that the attitudinal and cognitive domains and subscales loaded onto their respective factors. All factors had eigenvalues greater than one, and accounted for greater than $62 \%$ of the variance in each case. 
Table 2

Summary data for CDI-A-SF subscales of Career Planning, Career Exploration, World of Work Information and Decision Making; $N=2173$

\begin{tabular}{|c|c|c|c|c|c|c|c|c|c|c|c|c|c|}
\hline \multirow{2}{*}{\multicolumn{2}{|c|}{ Subscale/Domain }} & \multicolumn{2}{|c|}{$\begin{array}{c}\text { Year } 8 \\
N=568\end{array}$} & \multicolumn{2}{|c|}{$\begin{array}{c}\text { Year } 9 \\
N=396\end{array}$} & \multicolumn{2}{|c|}{$\begin{array}{l}\text { Year } 10 \\
N=459\end{array}$} & \multicolumn{2}{|c|}{$\begin{array}{l}\text { Year } 11 \\
N=419\end{array}$} & \multicolumn{2}{|c|}{$\begin{array}{l}\text { Year } 12 \\
N=331\end{array}$} & \multicolumn{2}{|c|}{$\begin{array}{c}\text { Total } \\
N=2173\end{array}$} \\
\hline & & $M$ & $S D$ & $M$ & $S D$ & $M$ & $S D$ & $M$ & $S D$ & $M$ & $S D$ & $M$ & $S D$ \\
\hline \multirow[t]{3}{*}{$\overline{\mathrm{CP}}$} & & 32.05 & 7.07 & 30.45 & 7.24 & 34.99 & 6.55 & 34.13 & 6.75 & 35.48 & 6.41 & 33.30 & 7.07 \\
\hline & $\mathrm{PO}$ & 19.13 & 4.21 & 17.96 & 4.33 & 20.88 & 3.99 & 20.35 & 4.04 & 20.89 & 4.07 & 19.79 & 4.28 \\
\hline & SI & 12.92 & 3.76 & 12.49 & 3.81 & 14.10 & 3.43 & 13.79 & 3.61 & 14.59 & 3.49 & 13.51 & 3.70 \\
\hline \multirow[t]{3}{*}{$\mathrm{CE}$} & & 18.11 & 4.60 & 17.58 & 4.67 & 20.31 & 4.37 & 20.77 & 4.55 & 21.49 & 4.63 & 19.50 & 4.80 \\
\hline & RA & 10.60 & 2.81 & 10.44 & 2.85 & 11.56 & 2.53 & 11.93 & 2.58 & 11.89 & 2.59 & 11.23 & 2.76 \\
\hline & RU & 7.51 & 2.93 & 7.14 & 2.91 & 8.75 & 2.92 & 8.84 & 2.94 & 9.60 & 2.92 & 8.28 & 3.05 \\
\hline WW & & 4.96 & 2.07 & 5.04 & 2.17 & 5.60 & 2.11 & 6.19 & 2.01 & 5.92 & 2.10 & 5.50 & 2.15 \\
\hline DM & & 3.53 & 1.87 & 3.55 & 1.92 & 3.89 & 2.08 & 4.53 & 1.95 & 4.41 & 2.28 & 3.94 & 2.05 \\
\hline
\end{tabular}

Note: $\mathrm{CP}=$ Career Planning, $\mathrm{PO}=$ Planning Orientation, $\mathrm{SI}=$ Specificity of Information, $\mathrm{CE}=$ Career Exploration, $\mathrm{RA}=\mathrm{Resources}$ Awareness, $\mathrm{RU}=$ Resource Use, WW = World of Work, DM = Decision Making. 
Table 3

Principal Axis Factor Analysis with Oblique Rotation of CDI-A-SF for Years 8-12 and Total Sample

\begin{tabular}{|c|c|c|c|c|c|c|c|c|c|c|c|c|}
\hline \multirow[b]{2}{*}{ Scale/Domain } & \multicolumn{2}{|c|}{$\begin{array}{c}\text { Year } 8 \\
N=568\end{array}$} & \multicolumn{2}{|c|}{$\begin{array}{c}\text { Year } 9 \\
N=396\end{array}$} & \multicolumn{2}{|c|}{$\begin{array}{c}\text { Year } 10 \\
N=459\end{array}$} & \multicolumn{2}{|c|}{$\begin{array}{l}\text { Year } 11 \\
N=419\end{array}$} & \multicolumn{2}{|c|}{$\begin{array}{l}\text { Year } 12 \\
N=331\end{array}$} & \multicolumn{2}{|c|}{$\begin{array}{c}\text { Total } \\
N=2173\end{array}$} \\
\hline & 1 & 2 & 1 & 2 & 1 & 2 & 1 & 2 & 1 & 2 & 1 & 2 \\
\hline$\overline{\mathrm{PO}}$ & .69 & .15 & .73 & .13 & .70 & -.17 & .74 & .18 & .64 & -.38 & .72 & .18 \\
\hline SI & .78 & -.07 & .73 & -.02 & .73 & .03 & .65 & -.00 & .56 & .05 & .72 & -.06 \\
\hline RA & .43 & .19 & .48 & .16 & .49 & -.12 & .47 & .20 & .66 & -.12 & .51 & .17 \\
\hline RU & .55 & -.15 & .54 & -.15 & .49 & .12 & .69 & -.20 & .56 & .11 & .60 & -.12 \\
\hline WW & -.01 & .81 & .04 & .70 & .01 & -.80 & -.01 & .78 & .11 & -.72 & .03 & .76 \\
\hline DM & .01 & .63 & -.02 & .83 & .02 & -.76 & .04 & .71 & -.11 & -.82 & -.01 & .76 \\
\hline Eigenvalues & 2.24 & 1.50 & 2.34 & 1.48 & 2.38 & 1.43 & 2.50 & 1.42 & 2.51 & 1.42 & 2.53 & 1.39 \\
\hline$\%$ Variance & 37.39 & 25.17 & 39.07 & 24.66 & 39.66 & 23.78 & 41.69 & 23.72 & 41.81 & 23.61 & 42.16 & 23.22 \\
\hline Inter-factor Cor & rrelation & .16 & & .20 & & -.24 & & .28 & & -.23 & & .28 \\
\hline
\end{tabular}

Note: $\mathrm{CP}=$ Career Planning, $\mathrm{PO}=$ Planning Orientation, $\mathrm{SI}=$ Specificity of Information, $\mathrm{CE}=\mathrm{Career}$ Exploration, RA $=$ Resources Awareness, RU $=$ Resource Use, $\mathrm{WW}=$ World of Work, $\mathrm{DM}=$ Decision Making. 
Comparison of CDI-A-SF and CDI-A

Associations between the CDI-A and the CDI-A-SF are reported in Table 4. Correlations between the CDI-A and the CDI-A-SF subscales, composite scales and total all exceeded .90, apart from World of Work Information subscale, which was still very satisfactory at .86 . Internal reliability coefficients are also reported in Table 4. CDI-A-SF coefficients are below those of the CDI-A, as would be expected for scales with fewer items. However, all coefficients are satisfactory at $\alpha>.70$, with the two composite scales losing very little in terms of internal reliability with $\alpha$ at .87 for the attitudinal composite scale and .82 for the cognitive scale.

Table 4

Bivariate Correlations between the CDI-A and the CDI-A-SF and Internal Reliability Coefficients; $N=2173$

Scale/Domain $\quad r \quad \alpha($ CDI-A) $\alpha($ CDI-A-SF)

\begin{tabular}{lllll}
\hline $\mathrm{CP}$ & & .95 & .91 & .87 \\
& PO & .92 & .85 & .81 \\
& SI & .95 & .90 & .86 \\
$\mathrm{CE}$ & & .92 & .79 & .73 \\
& $\mathrm{RA}$ & .87 & .71 & .72 \\
& $\mathrm{RU}$ & .89 & .74 & .64 \\
$\mathrm{WW}$ & & .86 & .80 & $.73^{1}$ \\
$\mathrm{DM}$ & .92 & .69 & $.70^{1}$ \\
$\mathrm{CDA}$ & .96 & .92 & .87 \\
$\mathrm{CDK}$ & .92 & .85 & $.82^{1}$ \\
COT & .96 & .91 & .87
\end{tabular}

Note: ${ }^{1}=$ Internal reliability calculated with the KuderRichardson 20 formula, all others were calculated using Cronbach alpha. $\mathrm{CP}=$ Career Planning, $\mathrm{PO}=$ Planning Orientation, $\mathrm{SI}=$ Specificity of Information, $\mathrm{CE}=$ Career Exploration, RA = Resources Awareness, RU = Resource Use, $\mathrm{WW}=$ World of Work, DM = Decision Making, $\mathrm{CDA}=$ Career Development Attitude, $\mathrm{CDK}=$ Career Development Knowledge, COT $=$ Career Orientation Total score. 


\section{Validity of the CDI-A-SF}

Validity was tested in two ways. First, by examining the degree to which associations obtained between the CDI-A-SF and other career related variables were similar to associations obtained for the CDI-A (concurrent validity); and second, by examining whether group differences reflected in the CDI-A-SF for gender and grade parallel differences identified for the CDI-A (construct validity). The scales available to test for concurrent validity were the Career Decision Scale (CDS-C and CDS-I), the Rosenberg Self-esteem Scale (RSE) and the Career Decision-Making Self-efficacy Scale-Short Form (CDMSE-SF). Correlations between the CDI-A-SF and the CDS, RSE and CDMSE-SF paralleled those of the CDI-A indicating that the CDI-A-SF relates to other variables in a manner similar to the CDI-A (see Table 5). Associations between the CDI-A-SF and the CDS, RSE and CDMSE-SF were in the expected direction, indicating good concurrent validity. For example, the CDA (attitude) composite scale of the CDI-A-SF was correlated .48 with career certainty (CDS-C; meaning that those with high career certainty reported more career planning and exploration), while the CDK (knowledge) composite scale was uncorrelated with career certainty (meaning that there was no difference between students who were certain and those who were uncertain on level of career knowledge, as would be expected).

A series of one-way ANOVAs was used to test for gender differences on the CDIA and the CDI-A-SF. The exact same pattern of differences emerged for the long and the short form of the CDI-A. For example, at Year 8, there were significant differences on CP, WW, DM, CDA, CDK, and COT, but not CE, while for the Total sample, there were significant differences on CE, WW, DM, CDA, CDK and COT, but not CP. A series of one-way ANOVAs was also used to test for school Grade 
differences. The near-exact same pattern also emerged here. A small number of differences did emerge between the CDI-A and the CDI-A-SF. For the CDI-A-SF, but not the CDI-A, there were significant differences between Year 8 and Year 9 on CP ( $p$ $<.003$ and $p=.135)$, significant differences between Year 8 and Year 9 on CDA $(p<$ .001 and $p=.15$ ), and no significant differences on CDA between Year 10 and Year $12(p=.006$ and $p=.13)$. Mean age differences on the CDI-A-SF were in the expected direction, with older students reporting higher levels of career maturity, as represented by the subscales, composite scales and total scale. These analyses, along with the factor analyses reported earlier, indicate support for the content and construct validity of the CDI-A-SF.

Table 5

Bivariate Correlations between the CDI-A, CDI-A-SF and the Career Decision Scale, the Rosenberg Self-esteem Scale and the Career Decision-Making Self-efficacy Scale$S F$

CDI-A

CDI-A-SF

Scale CDS-C CDS-I RSE CDMSE-SF CDS-C CDS-I RSE CDMSE-SF

\begin{tabular}{lllllllll}
\hline CP & .50 & .30 & .24 & .55 & .50 & .34 & .25 & .56 \\
CE & .33 & .17 & .13 & .41 & .31 & .19 & .12 & .40 \\
WW & .03 & .35 & .20 & .26 & .02 & .33 & .18 & .21 \\
DM & .00 & .37 & .20 & .24 & .01 & .38 & .20 & .22 \\
CDA & .48 & .28 & .22 & .56 & .48 & .32 & .23 & .56 \\
CDK & .02 & .40 & .22 & .27 & .01 & .40 & .21 & .24 \\
COT & .32 & .42 & .27 & .53 & .31 & .45 & .28 & .51
\end{tabular}

Note: $\mathrm{CP}=$ Career Planning, $\mathrm{PO}=$ Planning Orientation, $\mathrm{SI}=$ Specificity of Information, CE $=$ Career Exploration, RA = Resources Awareness, RU = Resource Use, WW = World of Work, DM = Decision Making, $\mathrm{CDA}=$ Career Development Attitude, $\mathrm{CDK}=$ Career Development Knowledge, COT = Career Orientation Total score, CDS-C = Certainty subscale from the CDS, CDS-I = Indecision subscale from CDS', RSE = Rosenberg Self-esteem Scale, CDMSE-SF = Career Decision-Making Self-Efficacy Scale - Short Form 


\section{Discussion}

Overall, the short form of the CDI-A, the 33-item CDI-A-SF, generated similar psychometric properties to the longer 72-item version. Items were selected for the CDI-A-SF that reflected construct coverage of the longer version, and met statistical criteria associated with corrected item-total correlations, item-other correlations, itemdifficulty and factor analysis. Ten items were retained in the Career Planning (CP) subscale. These items reflected representative construct coverage of the two domains of $\mathrm{CP}$ - four items from the Planning Orientation domain and six items from the Specificity of Information domain. Similarly, eight items were retained in the Career Exploration (CP) subscale, which were representative of the two domains of Resource Awareness and Resource Use. Eight items were retained in the World of Work Information (WW) subscale, and seven items were retained in the Career DecisionMaking (DM) subscale.

Factor analysis at the item level indicated that the Career Planning and Career Exploration subscale items all loaded on their respective factors, and factor analysis at the subscale level indicated that the attitudinal subscales of Career Planning and Career Exploration loaded appropriately on the attitudinal factor and that the World of Work Information and Career Decision-Making subscales loaded appropriately on the cognitive factors. These latter conclusions are very robust as the subscales loaded on the appropriate factors across the five individual samples of school Years 8-12. Strong associations were found between the CDI-A-SF and the CDI-A at the subscale, composite scale and total scale levels, and the internal reliability coefficients for the CDI-A-SF at all levels were satisfactory to good (ranging from .70-.87).

In addition, initial concurrent validity for the CDI-A-SF was demonstrated by associations in the expected direction with the Career Decision Scale, the Rosenberg 
Self-esteem Scale, and the Career Decision-Making Self-efficacy Scale-Short Form. Initial construct validity also was demonstrated by age and gender differences in the expected direction.

Thus, the 33-item CDI-A-SF can be considered a promising shortened version of the CDI-A, which can be utilised in situations where it is not possible or appropriate to use the full version. In the same way as for the CDI-A, the CDI-A-SF can be interpreted at the subscale $(\mathrm{CP}, \mathrm{CE}, \mathrm{WW}, \mathrm{DM})$, the composite scale (CDA, CDK) and total scale (COT) levels. There is less support for interpreting the CDI-A-SF at the domain level, because of the lower internal reliability at this level for the Resource Use domain; although it should be pointed out that the CDI-A Manual (Lokan, 1984) does not indicate interpretation at this level for the full version. While there is advice in the CDI-A Manual to interpret the CDI-A at the total score level (COT), we consider this inadvisable for both the CDI-A and the CDI-A-SF, as this involves collapsing the two independent attitudinal and cognitive domains, which is likely to lead to spurious interpretations. Future studies will need to replicate these findings of the psychometric properties of the CDI-A-SF and continue to test for its validity. In particular, the CDI-A-SF needs to be tested on other populations, such as with university students and unemployed youth, and importantly, studies need to be conducted that test for the predictive validity of the CDI-A-SF as well as the CDI-A. 


\section{References}

Betz, N. E. (1988). The assessment of career development and maturity. In W. B. Walsh \& S. H. Osipow (Eds.). Career decision making (pp. 77-136). Hillsdale, N.J.: Erlbaum.

Betz, N. E., Klein, K. L., \& Taylor, K. M. (1996). Evaluation of a short form of the Career Decision-Making Self-Efficacy Scale. Journal of Career Assessment, 4, 47-57.

Bingham, R., \& Krantz, J. (2001). Career and vocational assessment 1997-1998: A biennial review. Journal of Career Assessment, 9 (1), 1-24.

Clayton, L. \& Fletcher, J. (1994). Are realistic types really less career mature?: Year 10 differences in career maturity between Holland's work personality types. Australian Journal of Career Development, 3(1), 29-34.

Creed, P. A., \& Patton, W. (2003). Differences in career attitude and career knowledge for high school students with and without paid work experience. International Journal for Educational and Vocational Guidance, 3, 21-33.

Crites, J. (1971). The maturity of vocational attitudes in adolescence. Washington, DC: APGA.

Crites, J. (1976). A comprehensive model of career development in early adulthood. Journal of Vocational Behavior, 9, 105-118.

Crites, J., \& Savickas, M. (1995). Career Maturity Inventory: Sourcebook. Daytona, FL: Careerware.

Gorsuch, R. I. (1983). Factor analysis. Hillsdale, NJ: Erlbaum.

Gregory, R. J. (2000). Psychological testing: History, principles, and applications. Boston: Allyn \& Bacon. 
Hartman, B., Fuqua, D., \& Hartman, P. (1983). The construct validity of the Career Decision Scale administered to high school students. Vocational Guidance Quarterly, 31, 250-258.

Hinkin, T. (1998). A brief tutorial on the development of measures for use in survey questionnaire. Organizational Research Methods, 1, 104-121.

Kline, P. (2000). The handbook of psychological testing $\left(2^{\text {nd }}\right.$ Ed.). London: Routledge.

Levinson, E. M., Ohler, D. L., Caswell, S., \& Kiewra, K. (1998). Six approaches to the assessment of career maturity. Journal of Counseling and Development, 76, 475482.

Levy, B. (1987). A longitudinal study of vocational maturity. Unpublished doctoral dissertation, Monash University, Melbourne, Australia.

Lewis, D. M., Savickas, M. L., \& Jones, B. J. (1996). Career development predicts medical school success. Journal of Vocational Behavior, 49(1), 86-98.

Lokan, J. (1984). Manual of the Career Development Inventory - Australian Edition. Melbourne: ACER.

Lokan, J., \& Biggs, J. B. (1982). Student characteristics and motivational and process factors in relation to styles of career development. Journal of Vocational Behavior, 21, 1-16.

Lokan, J., \& Bryde, M. (1993). Career Development Inventory Australia-Revised Edition. Melbourne, VIC: Australian Council for Educational Research.

Luzzo, D. A. (1993). Predicting the career maturity of undergraduates: A comparison of personal, educational, and psychological factors. Journal of College Student Development, 34, 271-275. 
Ohler, D., \& Levinson, E. (1994). Assessment of career maturity in transdisciplinary vocational assessment. ERIC document, ED 371279.

Osipow, S. H. (1987). Career Decision Scale Manual. Odessa, FL: Psychological Assessment Resources Inc.

Osipow, S. H., Carney, C. G., Winer, J., Yanico, B., \& Koschier, M. (1976). The Career Decision Scale. Columbus, OH: Marathon Consulting \& Press.

Patton, W. \& Creed, P. A. (2001). Developmental issues in career maturity and career decision status. The Career Development Quarterly, 49, 336-351.

Patton, W., \& Lokan, J. (2001). Perspectives on Donald Super's construct of career maturity. International Journal of Educational and Vocational Guidance, 1, 31-48.

Patton, W., Watson, M., \& Creed, P. A. (In press). Career maturity of Australian and South African high school students: Developmental and contextual explanations. Australian Journal of Psychology.

Pinkney, J. W., \& Bozik, C. M. (1994). Career Development Inventory: A review. In J. T. Kapes, M. M. Mastie, \& E. A. Whitfield (Eds.). A counselor's guide to career assessment instruments ( $3^{\text {rd }}$ Edition, pp. 263-267). Alexandria, VA: National Career Development Association.

Raskin, P. (1998). Career maturity: The construct's validity, vitality, and viability. The Career Development Quarterly, 47, 32-35.

Rosenberg, M. (1965). Society and the adolescent self-image. Princeton: Princeton University Press.

Savickas, M. L. (1984). Career maturity: The construct and its appraisal. Vocational Guidance Quarterly, 32, 222-231. 
Savickas, M. L. \& Hartung, P. J. (1996). The Career Development Inventory in review: Psychometric and research findings. Journal of Career Assessment, 4(2), 171188.

Super, D. E. (1957). The psychology of careers. New York: Harper \& Row.

Super, D. E. (1990). A life -span, life-space approach to career development. In D. Brown \& L. Brooks (Eds), Career choice and development: Applying contemporary theories to practice (2nd ed., pp. 197-262). San Francisco, CA: Jossey-Bass.

Super, D. E., Osborne, W. L., Walsh, D. J., Brown, S. D., \& Niles, S. G. (1992). Developmental career assessment and counseling: The C-DAC model. Journal of Counseling and Development, 71, 74-80.

Super, D. E., Thompson, A. S., Jordaan, J. P., Lindeman, R. H., \& Myers, R. A. (1984). Career Development Inventory: Volume 2, Theoretical and Technical Manual. Palo Alto, CA: Consulting Psychologists Press.

Super, D. E., Thompson, A. S., Lindeman, R. H., Jordaan, J. P., \& Myers, R. A. (1981). Career Development Inventory. Palo Alto, CA: Consulting Psychologists Press.

Thompson, A. S., \& Lindeman, A. S. (1981). Career Development Inventory: Vol. 1, Users' Manual. Palo Alto, CA: Consulting Psychologists Press.

Thompson, A. S., \& Lindeman, A. S. (1982). Career Development Inventory college and university form supplement to User's Manual. Palo Alto, CA: Consulting Psychologists Press.

Thompson, A. S., \& Lindeman, R. H. (1984). Career Development Inventory Volume 2: Technical Manual. Palo Alto, CA: Consulting Psychologists Press. 
Wallace-Broscious, A., Serafica, F. C., \& Osipow, S. H. (1994). Adolescent career development: Relationships to self-concept and identity status. Journal of Research on Adolescence, 4(1), 127-149. 